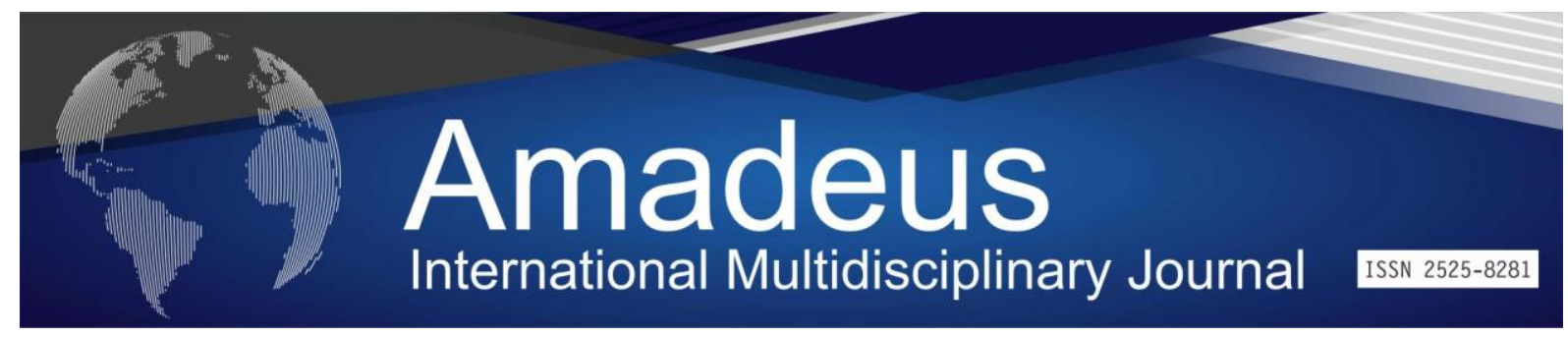

DOI: 10.14295/aimj.v5i9.127

\title{
Perception of Institutionalized Elderly about Quality of Life: an Integrative Review
}

Cícera Alves de Luna ${ }^{\text {, }}$ Allex Alves Sobral de Sousa ${ }^{2}$, Iasmim Belém Silva Queiroz,

Samyra Maria Lima

Sampaio $^{4}$,

Lucineide Coqueiro Gurgel ${ }^{5}$, Thayná Bezerra de Luna ${ }^{6}$,

Carmelita Maria Silva

Sousa ${ }^{7}$,

Abigail de Almeida

Cordeiro ${ }^{8}$,

Dayse Christina Rodrigues

Pereira Luz,

Willma José de Santana ${ }^{10}$.
Abstract: Aging is a physiological process that happens over time permeated by biological, psychosocial and cultural changes. Through the increase in life expectancy and, consequently, population aging worldwide, the Long Term Care Institutions for the Elderly (ILPI) stand out in caring for these elderly people, making it necessary to know what life is like for the elderly in this environment. Given the above, the study aimed to verify in the literature the perspective of institutionalized elderly about quality of life. Thus, the study is an integrative literature review with a qualitative approach, using Lilacs, Scielo and Medline databases as a means of research, taking advantage of the following Health Sciences Descriptors (DeCS): "Elderly", "Quality of life" and "institutionalized". The study sample consisted of 16 articles, which discussed the theme of the study, in which it was sought to verify the perception of institutionalized elderly about quality of life, it was decided to carry out two thematic categories: 01) Quality of Life for the Elderly Institutionalized, and 02) Perception of the Institutionalized Elderly. In view of the above, the study was able to show that the elderly who reside, live in a Long-Term Care Facility for the Elderly (ILPI), it is necessary to be active, dynamic, prepared to carry out their activities of daily living, in order to achieve their quality of life, harmonize health and promote healthy aging.

Keywords: Elderly, Quality of Life, Institutionalized.

\footnotetext{
${ }^{1}$ Master's student in Public Policy at Universidade Athenas College. Email: cicinha_luna@ hotmail.com;

${ }^{2}$ Master's student in Public Policy at Universidade Athenas College. Email: allexsobralfisio@ hotmail.com;

${ }^{3}$ Master's student in Public Policy at Universidade Athenas College. Email: iasminbelem@ hotmail.com;

${ }^{4}$ Master's student in Public Policy at Universidade Athenas College. Email: samyrasampaio3@ @otmail.com;

${ }^{5}$ Master's student in Public Policy at Universidade Athenas College. Email: lucineide.gurgel@yahoo.com.br;

${ }^{6}$ Master's student in Public Policy at Universidade Athenas College. Email: thaynabezerra@ hotmail.com;

${ }^{7}$ Master's student in Public Policy at Universidade Athenas College. Email: carmelitasilva11@ @hotmail.com;

${ }^{8}$ Master's student in Public Policy at Universidade Athenas College. Email: abigailcordeiro2@ @otmail.com;

${ }^{9}$ Post Doctoral Student in Health Sciences at the Health University Center of ABC-FMABC, Professor at the University

Center of Juazeiro do Norte - UNIJUAZEIRO. Email: dayse.dcrp@ hotmail.com;

${ }^{10}$ Post Doctoral Student in Health Sciences - FMABC, PhD in Biological Sciences at UFPE and Professor at Centro Universitário de Juazeiro do Norte - UNIJUAZEIRO and Faculty of Technology - FATEC - CARIRI. Email: wjsantana@hotmail.com.
} 


\section{Percepção dos Idosos Institucionalizados acerca da Qualidade de Vida: uma Revisão Integrativa}

\begin{abstract}
Resumo: O envelhecimento é um processo fisiológico que acontece ao longo do tempo permeado de mudanças biológicas, psicossociais e culturais. Mediante o aumento da expectativa de vida e consequentemente do envelhecimento populacional a nível mundial as Instituição de Longa Permanência para Idosos (ILPI) ganham destaque no cuidar desses idosos, fazendo-se necessário assim conhecer como é a vida dos idosos neste ambiente. Diante do exposto o estudo objetivou verificar na literatura a perspectiva dos idosos institucionalizados acerca da qualidade de vida. Desta forma o estudo trata-se de uma revisão integrativa da literatura com abordagem qualitativa, utilizando como meio de pesquisa, as bases de dados Lilacs, Scielo e Medline, prevalecendo-se dos seguintes Descritores em Ciências da Saúde (DeCS): "Idoso", "qualidade de vida" e "institucionalizados". A amostra do estudo contou com 16 artigos, que discorreram sobre o tema do estudo, onde buscou-se verificar a percepção dos idosos institucionalizados acerca da qualidade de vida, optou-se pela realização de duas categorias temáticas: 01) Qualidade de Vida do Idoso Institucionalizado, e 02) Percepção do Idoso Institucionalizado. Diante do exposto, o estudo foi capaz de mostrar que o idoso que reside, habita em Instituição de Longa Permanência para Idosos (ILPI) é necessário estar ativo, dinâmico, preparado a realizar suas atividades de vida diária, a fim de conseguir sua qualidade de vida, harmonizar saúde e favorecer um envelhecimento saudável.
\end{abstract}

Palavras-chave: Idoso, Qualidade de Vida, Institucionalizado.

\section{Introdução}

Levando em consideração que o indivíduo idoso se faz crescente e que as Instituição de Longa Permanência para Idosos (ILPI) se representa na melhor escolha para uma parte de idosos e seus familiares, serve que, cada vez mais, essas disponham de infraestrutura e recursos humanos aptos para bem cuidar dessa clientela, conhecendo os aspectos relacionadas às divergentes faixas etárias e, buscando a estabilidade da liberdade e da qualidade de vida dos idosos institucionalizados (Silva et al., 2019).

A família tem um valor constitucional na vida e na permanência do bem-estar do idoso, já que pode ser avaliada um manancial de apoio àqueles que precisam de determinados cuidados. Porém, a convivência entre famílias pode provocar subversões e dificuldades de relacionamento, que podem se afrontar assim como os membros da família não são cômodos de abranger o comportamento de seus idosos ou bem como não conseguem exercer o cargo de cuidadores. Com o objetivo de que aqueles que não conseguem amparo familiar quando 
precisam de ajuda para a concretização de atividades da vida diária resta a esperança de integração em uma instituição de longa permanência para idosos - ILPI (Néri et al., 2012).

Identificar os fatores que levam à institucionalização será necessário para que os familiares e os profissionais de saúde observem a viabilidade de prevenção e consigam distinguir quando a institucionalização é, de fato, indicada. Os dirigentes e órgãos fiscalizadores das ILPI, mediante maior conhecimento sobre os indicadores da institucionalização, apontar medidas de melhor abrigo e manejo dessa população (Lini et al., 2016). A institucionalização é um resultado discrepante da fragilidade do idoso, visto que os fatores surgem do abandono familiar, isolamento e exclusão. Tais motivos que contribuem para abertura de sentimentos, pensamentos e atitudes negativas. Que implica no estado emocional, mental e a própria qualidade de vida do idoso (Cordeiro et al., 2015).

Acredita-se que, pelas deslocações e dilemas sociais, somada ao acréscimo do número de idosos, a demanda por ILPI que disponibilizem atendimento a esse público vem crescendo constantemente. Esse acontecimento depende de fatores culturais, condição do suporte familiar e disponibilidade dos serviços alternativos. A legislação brasileira recomenda que os cuidados com a pessoa idosa devem ser exercidos pela família, no entanto, muitas delas não dispõem de tempo e muito menos condições para assumir com os cuidados de seus idosos, sendo as Instituições de Longa Permanência para Idosos (ILPI) uma possibilidade para preservar a vida do idoso (Camarano e Kanso, 2010).

Portanto, considera que toda essa problemática vivido pelo idoso, principalmente quando institucionalizado, consiga comprometer de diversas formas a sua qualidade de vida, motivo este que tem ocupado lugar de interesse sobre a questão do envelhecimento. Então, acredita-se que este estudo tornou relevante, pois os resultados delimitar as ações e os cuidados com os idosos institucionalizados, proporcionando da melhor forma a fim de reduzir a problemática apresentada.

\section{Metodologia}

O presente estudo determina-se como uma revisão integrativa da literatura com abordagem qualitativa, a qual permite abranger temáticas ou dificuldades acentuadas para o campo da saúde e das políticas públicas, por meio da compreensão, análise crítica e síntese da ciência, acerca do objeto pesquisado. O processo de revisão integrativa é um enfoque que admite a abrangência de estudos que aceitam distantes metodologias, ou seja, experimental e de análise não experimental (Botelho et al., 2011). 
O propósito inicial deste método de estudo é conseguir um profundo entendimento de um determinado fenômeno baseando-se em pesquisas anteriores, sendo necessário seguir padrões de rigor metodológico, clareza na apresentação dos resultados, de maneira que o leitor consiga identificar as propriedades reais dos estudos incluídos na revisão (Mendes et al., 2008). Nesse contexto, entendendo a finalidade do método de revisão integrativa, a pesquisa foi estruturada nos seguintes passos: Identificação do tema e seleção da hipótese; busca na literatura; categorização dos estudos; análise de dados, interpretação dos resultados e síntese do conteúdo.

\section{$1^{\circ}$ Fase: Identificação do tema e pergunta norteadora}

Extremamente importante essa fase da revisão. Entretanto por meio da definição da questão norteadora, que são determinados quais os estudos que serão incluídos, os meios adotados para a identificação e as informações de cada estudo. Sendo clara e específica.

\section{$2^{\circ}$ Fase: Critérios de Inclusão/ Exclusão/ Amostragem}

Com base no estudo de Whittemore e Knafl (2005), após a seleção do tema pelo revisor e a formulação da questão de pesquisa, foi iniciado a pesquisa nas bases de dados para identificação dos estudos que foram incluídos na revisão. A internet é um instrumento importante nesta busca, pois as bases de dados possuem acesso eletrônico. A escolha dos estudos para a avaliação crítica foi essencial, a fim de se obter a validade interna da revisão.

Para tanto, optou-se por realizar um levantamento bibliográfico tendo como fonte de pesquisa as bases de dados: Literatura Latino-Americana e do Caribe em Ciências da Saúde (LILACS), Scientific Eletronic Library Online (SCIELO) e Medical Literature Analysis and Retrieval System (Online MEDLINE). Todavia, de maneira coerente, conforme validação das palavras-chave no portal dos Descritores em Ciência da Saúde (DeCS), para o levantamento das produções cientificas foram utilizados como descritores, "Idoso", "Qualidade de vida" e "Institucionalização".

De modo sequencial, foram utilizados como critérios de inclusão dos estudos para esta revisão integrativa: trabalhos publicados na íntegra, disponíveis em língua portuguesa, e que respondia a questão da pesquisa. Desta forma, optou-se por estabelecer para a seleção dos artigos, estudos que fossem publicados no período de 2014 a 2019, por se tratar de um período que fornece informações mais atualizadas acerca do assunto. Por outro lado, como 
critérios de exclusão destacam-se os artigos que não foram adquiridos na íntegra, artigos repetidos nas respectivas bases de dados mencionadas anteriormente, além de estudos publicados em língua estrangeira, e que não estejam dentro do período estabelecido.

Em virtude das características específicas para o acesso das bases de dados selecionadas LILACS, SCIELO e MEDLINE, os métodos utilizados para localizar os artigos foram adaptados para cada uma, tendo como eixo norteador a indagação conforme estabelecida na primeira fase do estudo, assim como obedecessem aos objetivos e aos critérios de inclusão e exclusão da revisão integrativa, previamente especificados para manter a coerência na busca e aprovação dos artigos e evitar possíveis vieses.

A busca foi realizada pelo acesso online em um único dia. A amostra final desta revisão integrativa contou com 16 artigos. Utilizou-se uma ferramenta de coleta de dados, preenchida com base em cada estudo incluso na pesquisa o que, desse modo, auxiliou na coleta de dados para que os objetivos da pesquisa fossem obtidos. Na base de dados SCIELO, o cruzamento ocorreu através da associação entre os descritores: "Idoso", "Qualidade de Vida" e "Institucionalizado", e resultou em um total de 06 artigos. De acordo com os critérios de inclusão, restaram 03 artigos.

Na base de dados LILACS, o cruzamento ocorreu através da associação entre os descritores: "Idoso", "Qualidade de Vida" e "Institucionalizado", e resultou em um total de 23 artigos. De acordo com os critérios de inclusão, restaram 12 artigos. Na base de dados MEDLINE, o cruzamento ocorreu através da associação entre os descritores, "Idoso", "Qualidade de Vida" e "Institucionalizado", e resultou em um total de 06 artigos. De acordo com os critérios de inclusão, restaram 01 artigos. Para melhor compreensão da pesquisa, a (Figura 01) ilustra a seleção dos artigos.

\section{$3^{\circ}$ Fase: Categorização dos Estudos}

De acordo com Broome (2000), o revisor tem como objetivo nesta etapa, organizar e abreviar as informações de maneira sucinta, formando um banco de dados de fácil acesso e utilização. Desse modo, conforme semelhança entre os assuntos foram estabelecidas duas categorias temáticas de modo organizado e sistemático, sendo estas: Qualidade de Vida do Idoso Institucionalizado e Percepção do Idoso Institucionalizado, afim de que possibilite uma melhor analise e entendimento dos estudos, conforme mostra o (Quadro 01). 
Figura 01 - Fluxograma de seleção dos estudos da revisão integrativa. Juazeiro do Norte, 2020.

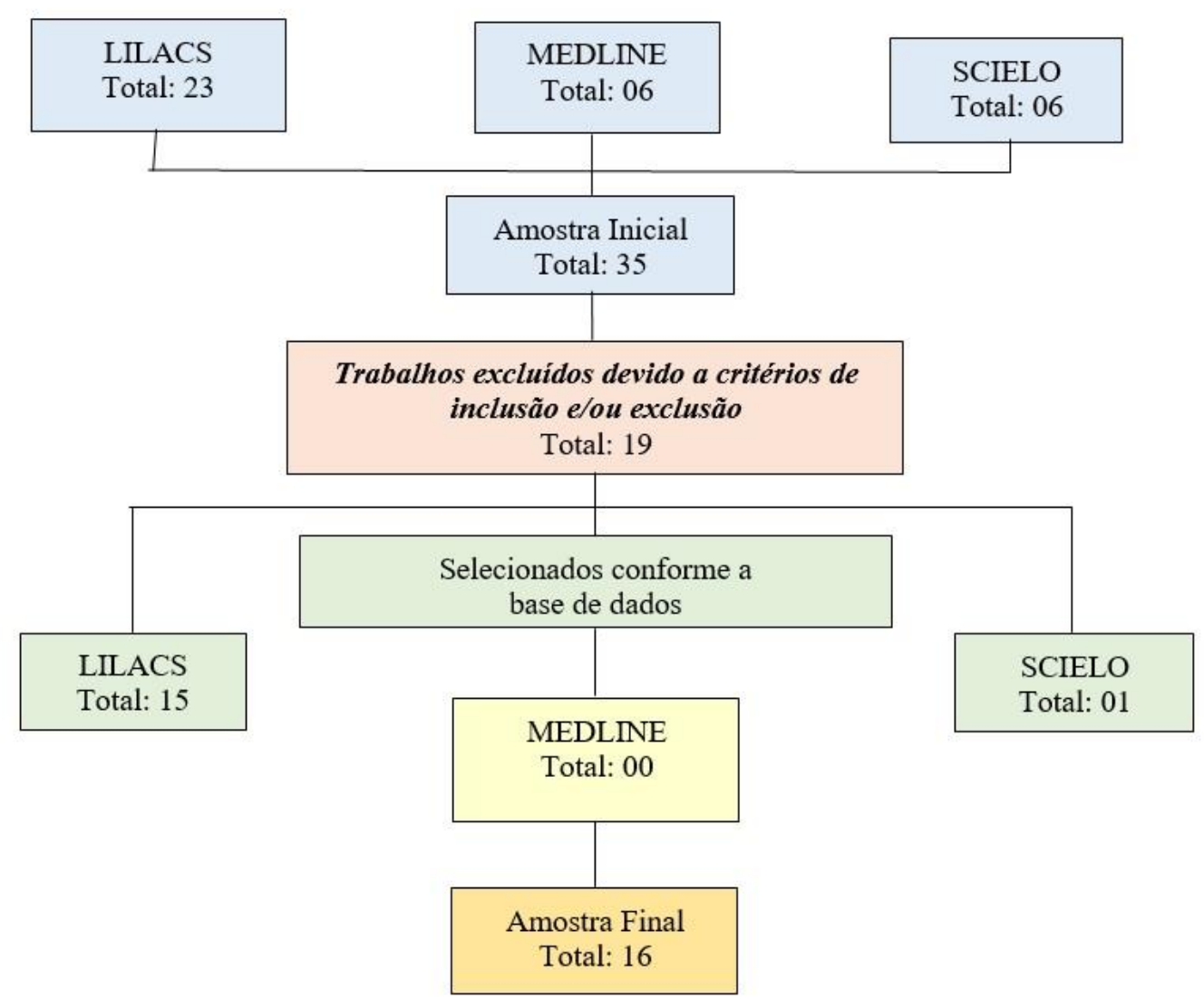

Fonte: dados da Pesquisa, 2020.

Quadro 01 - Categorização dos artigos conforme leitura e dados em comum das produções científicas.

\begin{tabular}{|c|c|}
\hline CATEGORIAS & $\mathbf{N}^{\mathbf{0}}$ DO ARTIGO \\
\hline Qualidade de Vida do Idoso Institucionalizado & $\begin{array}{c}01 / 03 / 04 / 05 / 06 / 07 / 08 / 10 / 11 / \\
13 / 14 / 15 / 16\end{array}$ \\
\hline Percepção do Idoso Institucionalizado & $02 / 09 / 12$ \\
\hline
\end{tabular}

Fonte: dados da Pesquisa, 2020.

A $3^{a}$ fase caracteriza-se pela criação de instrumentos que organizem adequadamente a extração das informações dos estudos selecionados. Ela estabelece a confiança dos resultados e fortalece as conclusões sobre o estado atual do tema investigado (MENDES KDS, et al.,2008). Para isso, a coleta de dados foi facilitada por meio da construção de um formulário que contemplou os critérios de inclusão, desatacando-se as seguintes características: identificação do trabalho (Título do artigo, Autor(es), revista/ano, objetivos, métodos, 
resultados/considerações); as fonte selecionadas para as buscas dos artigos foram: Literatura Latino-Americana e do Caribe em Ciências da Saúde (LILACS), Scientific Eletronic Library Online (SCIELO) e Medical Literature Analysis and Retrieval System Online (MEDLINE), delineamento do estudo (quantitativo, qualitativo, quantitativo, revisão de literatura, revisão sistemática, metanálise, estudo de caso e não se aplica); objetivos da pesquisa e síntese dos principais resultados.

Para a coleta de dados dos artigos selecionados, foi realizada leitura e fichamento dos artigos, escolhendo as partes mais importantes sobre a temática do estudo, que possibilitaram responder às questões norteadoras feitas na primeira fase do trabalho. Após a seleção dos artigos que responderam aos critérios de inclusão, os mesmos foram impressos e catalogados em ordem numérica e organizados de acordo com o ano de publicação. Em seguida foi realizada a leitura minuciosa dos artigos, a fim de analisá-los com base nos objetivos estabelecidos.

\section{$4^{0}$ Fase: Avaliação dos Estudos Incluídos na Revisão}

Esse tipo de pesquisa requer uma abordagem organizada para atribuir severidade as características de cada estudo. Os estudos foram avaliados criteriosamente quanto à legitimidade, qualidade metodológica e importância da informação e foram apresentados em quadros com informações relevantes de cada artigo, possibilitando a análise e comparação dos mesmos com o conhecimento teórico, identificando lacunas pertinentes ao assunto e atendendo o escopo da pesquisa. Nessa fase também foram apresentados os resultados que consistiram em cruzar as informações retiradas dos artigos e mostrar os avanços no conhecimento bem como suas falhas. Ao fim da primeira análise da amostra pôde-se concluir que a análise dos artigos selecionados permitia responder as questões norteadoras do estudo.

\section{$5^{\circ}$ Fase: Interpretação dos resultados}

Esta etapa segundo Mendes et al., (2008), corresponde à fase de discussão dos principais resultados na revisão integrativa. Logo, os revisores fundamentados nos resultados da avaliação crítica dos estudos incluídos foram comparados, interpretados e debatidos no desenvolvimento do estudo. 


\section{$6^{a}$ Fase: Apresentação da revisão integrativa/síntese do conhecimento}

Esta etapa baseado no estudo de Roman e Friedlander (2008), consiste na elaboração do documento que deve contemplar a descrição das etapas percorridas pelo revisor e os principais resultados evidenciados da análise dos artigos incluídos. Portanto, para melhor discutir o enfoque dos trabalhos analisados, optou-se pela discussão das categorias a fim de facilitar a compreensão e a síntese do conhecimento. Igualmente, por ser um trabalho bibliográfico, o mesmo não foi submetido ao Comitê de Ética em Pesquisa (CEP).

\section{Resultados e Discussão}

Durante a coleta de dados foram selecionados um total de 16 publicações científicas por condizerem com os fatores de inclusão e apresentarem importância para o estudo. Logo, a análise do conteúdo bibliográfico direcionou a elaboração de um quadro, sendo este, organizado e apresentado por número do artigo, título, autor(es), ano, revista, objetivo(s), método, bem como resultados/considerações, tendo em vista como aspectos importantes a serem analisados na revisão. O (Quadro 02) apresenta o resumo dos estudos.

Quadro 02 - Caracterização dos artigos incluídos no estudo.

\begin{tabular}{|c|c|c|c|c|c|c|}
\hline $\mathbf{N}^{\mathbf{o}}$ & Título & $\begin{array}{l}\text { Autor(es)/ } \\
\text { Ano }\end{array}$ & Revista & Objetivo(s) & Método & $\begin{array}{c}\text { Resultados/ } \\
\text { considerações }\end{array}$ \\
\hline 01 & $\begin{array}{l}\text { Condições de } \\
\text { saúde de idosos } \\
\text { residentes em } \\
\text { Instituição de } \\
\text { Longa } \\
\text { Permanência } \\
\text { segundo } \\
\text { necessidades } \\
\text { humanas básicas }\end{array}$ & $\begin{array}{l}\text { Oliveira et } \\
\text { al. / (2014) }\end{array}$ & $\begin{array}{l}\text { Revista } \\
\text { Brasileira } \\
\text { de } \\
\text { Enfermag } \\
\text { em }\end{array}$ & $\begin{array}{l}\text { Caracterizar } \\
\text { os idosos } \\
\text { residentes em } \\
\text { ILPIs segundo as } \\
\text { variáveis: sexo, } \\
\text { idade, } \\
\text { escolaridade; causa } \\
\text { de admissão e } \\
\text { tempo de } \\
\text { permanência; e } \\
\text { descrever as } \\
\text { condições de saúde } \\
\text { dos idosos segundo } \\
\text { a teoria das NHB. }\end{array}$ & $\begin{array}{c}\text { Estudo } \\
\text { transversal } \\
\text { de } \\
\text { abordagem } \\
\text { quantitativa }\end{array}$ & $\begin{array}{l}\text { Os distúrbios } \\
\text { do sono podem } \\
\text { resultar em } \\
\text { prejuízos na rotina } \\
\text { diária e na saúde } \\
\text { dos idosos } \\
\text { residentes nas ILP. } \\
\text { Como também a } \\
\text { realização de } \\
\text { atividade física, } \\
\text { assim como a } \\
\text { inatividade foram } \\
\text { considerados } \\
\text { Sedentários. A } \\
\text { pratica regular de } \\
\text { atividade física } \\
\text { contribui para uma } \\
\text { melhor qualidade de } \\
\text { vida entre as } \\
\text { pessoas } \\
\text { Idosas. }\end{array}$ \\
\hline 02 & $\begin{array}{c}\text { Idosos } \\
\text { institucionalizado } \\
\text { s: organização } \\
\text { cronológica das }\end{array}$ & $\begin{array}{l}\text { Mansano- } \\
\text { schlosser et } \\
\text { al. / (2014) }\end{array}$ & $\begin{array}{l}\text { Revista } \\
\text { Brasileira } \\
\text { de }\end{array}$ & $\begin{array}{c}\text { Identificar a } \\
\text { percepção de } \\
\text { idosos } \\
\text { institucionalizados }\end{array}$ & $\begin{array}{c}\text { Estudo } \\
\text { descritivo } \\
\text { Transversal }\end{array}$ & $\begin{array}{c}\text { A maioria dos } \\
\text { idosos despertava } \\
\text { entre seis e sete } \\
\text { horas da manhã, por }\end{array}$ \\
\hline
\end{tabular}




\begin{tabular}{|c|c|c|c|c|c|c|}
\hline & $\begin{array}{l}\text { rotinas diárias e } \\
\text { qualidade do } \\
\text { sono }\end{array}$ & & $\begin{array}{c}\text { Enfermag } \\
\text { em }\end{array}$ & $\begin{array}{c}\text { quanto a } \\
\text { organização } \\
\text { cronológica das } \\
\text { rotinas diárias e } \\
\text { quanto a qualidade } \\
\text { do sono. }\end{array}$ & & $\begin{array}{l}\text { estarem habituados. } \\
\text { Preferiam tomar } \\
\text { banho de manhã, } \\
\text { almoçavam as onze } \\
\text { e meia, jantavam as } \\
\text { cinco e meia da } \\
\text { tarde e dormiam } \\
\text { entre } 19 \text { e } 22 \text { horas. }\end{array}$ \\
\hline $\mathbf{0 3}$ & $\begin{array}{l}\text { O impacto das } \\
\text { alterações de } \\
\text { deglutição } \\
\text { na qualidade de } \\
\text { vida de idosos } \\
\text { Institucionalizado } \\
\text { s }\end{array}$ & $\begin{array}{l}\text { Cardoso et } \\
\text { al. / (2014) }\end{array}$ & $\begin{array}{l}\text { Revista } \\
\text { Kairós } \\
\text { Gerontolo } \\
\text { gia }\end{array}$ & $\begin{array}{c}\text { Investigar o } \\
\text { impacto das } \\
\text { Alterações de } \\
\text { deglutição na } \\
\text { qualidade de vida } \\
\text { de idosos } \\
\text { institucionalizados. }\end{array}$ & $\begin{array}{l}\text { Estudo de } \\
\text { abordagem } \\
\text { qualitativa. }\end{array}$ & $\begin{array}{l}\text { Podendo perceber a } \\
\text { importância da } \\
\text { avaliação aos idosos } \\
\text { no momento das } \\
\text { refeições e } \\
\text { desenvolvendo } \\
\text { algumas estratégias } \\
\text { para evitar } \\
\text { engasgos, dentre } \\
\text { foram não falar } \\
\text { durante a } \\
\text { alimentação, comer } \\
\text { devagar, cortar a } \\
\text { comida em pedaços } \\
\text { pequenos, evitar } \\
\text { consistências e } \\
\text { tomar água para } \\
\text { auxiliar a deglutição } \\
\text { de alimentos } \\
\text { sólidos. }\end{array}$ \\
\hline 04 & $\begin{array}{c}\text { Avaliação das } \\
\text { funções } \\
\text { cognitivas, } \\
\text { Qualidade de } \\
\text { sono, tempo de } \\
\text { reação } \\
\text { E risco de quedas } \\
\text { em idosos } \\
\text { Institucionalizado } \\
\text { s }\end{array}$ & $\begin{array}{l}\text { Gonçalves } \\
\text { et al. / } \\
\text { (2014) }\end{array}$ & $\begin{array}{c}\text { Estudo } \\
\text { Interdisci } \\
\text { plinar } \\
\text { Envelhece } \\
\mathrm{r}\end{array}$ & $\begin{array}{c}\text { Avaliar } \\
\text { as funções } \\
\text { cognitivas, a } \\
\text { qualidade de sono, } \\
\text { o tempo de reação } \\
\text { e o risco de quedas } \\
\text { em idosos } \\
\text { institucionalizados. }\end{array}$ & $\begin{array}{l}\text { Estudo } \\
\text { cognitivo }\end{array}$ & $\begin{array}{l}\text { A possibilidade de } \\
\text { quedas entre os } \\
\text { idosos é } \\
\text { reconhecida como } \\
\text { um } \\
\text { importante } \\
\text { problema de saúde } \\
\text { pública. } \\
\text { A preocupação com } \\
\text { a possibilidade de } \\
\text { quedas do idoso é } \\
\text { deixar o indivíduo } \\
\text { impotente, indefeso } \\
\text { e fragilizado para } \\
\text { tomar suas próprias } \\
\text { decisões. }\end{array}$ \\
\hline 05 & $\begin{array}{c}\text { Oficinas } \\
\text { terapêuticas para } \\
\text { a reabilitação } \\
\text { psíquica } \\
\text { de pacientes } \\
\text { institucionalizado } \\
\text { s em decorrência } \\
\text { da hanseníase }\end{array}$ & $\begin{array}{l}\text { Leite e } \\
\text { Caldeira / } \\
\text { (2015) }\end{array}$ & $\begin{array}{l}\text { Ciência \& } \\
\text { Saúde } \\
\text { Coletiva }\end{array}$ & $\begin{array}{l}\text { Avaliar o impacto } \\
\text { de tais medidas. }\end{array}$ & $\begin{array}{l}\text { Estudo de } \\
\text { intervenção } \\
\text { aberto, com } \\
\text { abordagem } \\
\text { quantitativa }\end{array}$ & $\begin{array}{c}\text { Os escores do } \\
\text { questionário de } \\
\text { qualidade de vida } \\
\text { antes e após as } \\
\text { oficinas terapêuticas } \\
\text { são apresentados na } \\
\text { Tabela 3. As } \\
\text { alterações foram } \\
\text { significativas para } \\
\text { os domínios Físico, } \\
\text { Psicológico e de } \\
\text { Meio Ambiente, } \\
\text { não se registrando } \\
\text { diferença } \\
\text { significativa apenas } \\
\text { para o domínio de } \\
\text { relações sociais. }\end{array}$ \\
\hline
\end{tabular}




\begin{tabular}{|c|c|c|c|c|c|c|}
\hline 06 & $\begin{array}{c}\text { Percepção de } \\
\text { idosos, } \\
\text { moradores de } \\
\text { uma instituição } \\
\text { de longa } \\
\text { permanência de } \\
\text { um município do } \\
\text { interior do Rio } \\
\text { Grande } \\
\text { do Sul, sobre } \\
\text { qualidade de vida } \\
\end{array}$ & $\begin{array}{c}\text { Brandão e } \\
\text { Zatt / } \\
(2015)\end{array}$ & $\begin{array}{l}\text { Revista } \\
\text { Aletheia }\end{array}$ & $\begin{array}{c}\text { Investigar a } \\
\text { percepção } \\
\text { sobre qualidade de } \\
\text { vida, sob a } \\
\text { perspectiva de } \\
\text { idosos moradores } \\
\text { de uma instituição } \\
\text { de longa } \\
\text { permanência. }\end{array}$ & $\begin{array}{c}\text { Estudo de } \\
\text { abordagem } \\
\text { qualitativa }\end{array}$ & $\begin{array}{c}\text { Através dos relatos } \\
\text { podemos perceber } \\
\text { que inicialmente há } \\
\text { certa desconfiança } \\
\text { com relação à } \\
\text { institucionalização, } \\
\text { mas que grande } \\
\text { parte dos idosos } \\
\text { está satisfeita com o } \\
\text { atendimento } \\
\text { prestado. }\end{array}$ \\
\hline 07 & $\begin{array}{c}\text { Qualidade de } \\
\text { vida do idoso } \\
\text { fragilizado e } \\
\text { institucionalizado }\end{array}$ & $\begin{array}{l}\text { Cordeiro et } \\
\text { al. / (2015) }\end{array}$ & $\begin{array}{c}\text { Acta Paul } \\
\text { Enfermag } \\
\text { em }\end{array}$ & $\begin{array}{l}\text { Avaliar a qualidade } \\
\text { de vida de idosos } \\
\text { frágeis } \\
\text { institucionalizados. }\end{array}$ & $\begin{array}{l}\text { Estudo } \\
\text { transversal }\end{array}$ & $\begin{array}{c}\text { Mesmo não sendo } \\
\text { consenso de que a } \\
\text { fragilidade } \\
\text { influencie } \\
\text { negativamente na } \\
\text { qualidade de vida } \\
\text { dos indivíduos, } \\
\text { é crescente o } \\
\text { interesse por } \\
\text { estudar qualidade } \\
\text { de vida em idosos } \\
\text { frágeis } \\
\text { institucionalizados. }\end{array}$ \\
\hline 08 & $\begin{array}{l}\text { Autopercepção } \\
\text { da saúde em } \\
\text { idosos } \\
\text { institucionalizado } \\
\text { s }\end{array}$ & $\begin{array}{c}\text { Jerez-Roig } \\
\text { et al. / } \\
\text { (2016) }\end{array}$ & $\begin{array}{l}\text { Ciência } \\
\& \text { Saúde } \\
\text { Coletiva }\end{array}$ & $\begin{array}{c}\text { Verificar a } \\
\text { autopercepção da } \\
\text { saúde em idosos } \\
\text { institucionalizados, } \\
\text { e também os } \\
\text { fatores associados } \\
\text { à percepção ruim } \\
\text { da saúde. }\end{array}$ & $\begin{array}{c}\text { Estudo } \\
\text { transversal } \\
\text { de } \\
\text { abordagem } \\
\text { quantitativa }\end{array}$ & $\begin{array}{l}\text { Mediante a análise } \\
\text { multivariada, foi ve- } \\
\text { rificado que a } \\
\text { autopercepção } \\
\text { negativa da saúde } \\
\text { em idosos } \\
\text { institucionalizados } \\
\text { esteve associada à } \\
\text { perda involuntária } \\
\text { de peso durante o } \\
\text { último ano. }\end{array}$ \\
\hline 09 & $\begin{array}{c}\text { Descrição dos } \\
\text { sintomas de } \\
\text { Ansiedade e } \\
\text { Depressão em } \\
\text { idosos } \\
\text { institucionalizado } \\
\text { s no interior da } \\
\text { Bahia, Brasil }\end{array}$ & $\begin{array}{l}\text { Gomes e } \\
\text { Reis / } \\
\text { (2016) }\end{array}$ & $\begin{array}{l}\text { Revista } \\
\text { Kairós } \\
\text { Gerontolo } \\
\text { gia }\end{array}$ & $\begin{array}{c}\text { Avaliar os níveis } \\
\text { de ansiedade e } \\
\text { depressão em } \\
\text { uma população de } \\
\text { idosos } \\
\text { institucionalizados, } \\
\text { dos Municípios de } \\
\text { Itapetinga, Jequié e } \\
\text { Vitória da } \\
\text { Conquista, no } \\
\text { estado da Bahia, } \\
\text { Brasil. }\end{array}$ & $\begin{array}{c}\text { Estudo } \\
\text { descritivo e } \\
\text { exploratório } \\
\text { de } \\
\text { abordagem } \\
\text { quantitativa }\end{array}$ & $\begin{array}{l}\text { Foram alcançados } \\
\text { significativos } \\
\text { progressos, mas } \\
\text { também se observa } \\
\text { a necessidade de } \\
\text { ampliação das ações } \\
\text { relacionadas } \\
\text { ao campo das } \\
\text { políticas públicas } \\
\text { para a terceira } \\
\text { idade. }\end{array}$ \\
\hline 10 & $\begin{array}{c}\text { Qualidade de } \\
\text { vida sob a óptica } \\
\text { da pessoa } \\
\text { Idosa } \\
\text { institucionalizada }\end{array}$ & $\begin{array}{c}\text { Lima et al. / } \\
\text { (2016) }\end{array}$ & $\begin{array}{l}\text { Revista } \\
\text { Brasileira } \\
\text { Promoção } \\
\text { Saúde }\end{array}$ & $\begin{array}{l}\text { Analisar o conceito } \\
\text { atribuído à } \\
\text { qualidade de vida } \\
\text { sob a ótica de } \\
\text { idosos } \\
\text { institucionalizados. }\end{array}$ & $\begin{array}{c}\text { Estudo } \\
\text { descritivo } \\
\text { de } \\
\text { abordagem } \\
\text { qualitativa }\end{array}$ & $\begin{array}{l}\text { Os achados do } \\
\text { presente estudo } \\
\text { mostram que o } \\
\text { idoso que reside em } \\
\text { ILP precisa estar } \\
\text { ativo, apto a } \\
\text { desenvolver suas } \\
\text { atividades de vida } \\
\text { diária para obter } \\
\text { QV e promover } \\
\text { saúde e propiciar } \\
\text { um envelhecimento }\end{array}$ \\
\hline
\end{tabular}




\begin{tabular}{|c|c|c|c|c|c|c|}
\hline & & & & & & saudável. \\
\hline 11 & $\begin{array}{l}\text { Programas de } \\
\text { atividade física } \\
\text { para pessoas } \\
\text { idosas } \\
\text { institucionalizada } \\
\text { s contextos e } \\
\text { práticas }\end{array}$ & $\begin{array}{l}\text { Silva e } \\
\text { Neves / } \\
(2017)\end{array}$ & $\begin{array}{l}\text { Revista } \\
\text { Kairós- } \\
\text { Gerontolo } \\
\text { gia }\end{array}$ & $\begin{array}{l}\text { Caracterizar dos } \\
\text { PAF relativamente } \\
\text { à: regularidade e } \\
\text { duração, tipo de } \\
\text { atividades, critérios } \\
\text { de escolha das } \\
\text { atividades e } \\
\text { intensidade de } \\
\text { esforço aplicado } \\
\text { nas sessões. } \\
\end{array}$ & $\begin{array}{c}\text { Estudo } \\
\text { Semi- } \\
\text { Estruturada } \\
\text { de } \\
\text { abordagem } \\
\text { qualitativa }\end{array}$ & $\begin{array}{c}\text { Neste ponto } \\
\text { apresentaremos os } \\
\text { dados divididos em } \\
\text { função das várias } \\
\text { categorias de } \\
\text { análise que } \\
\text { correspondem aos } \\
\text { objetivos do } \\
\text { presente estudo. }\end{array}$ \\
\hline 12 & $\begin{array}{c}\text { Reflexões acerca } \\
\text { dos Impactos } \\
\text { Psicossociais } \\
\text { da } \\
\text { Institucionalizaçã } \\
\text { o de Idosos no } \\
\text { Brasil }\end{array}$ & $\begin{array}{l}\text { Abreu et al. } \\
\text { / (2017) }\end{array}$ & $\begin{array}{l}\text { Revista } \\
\text { Kairós- } \\
\text { Gerontolo } \\
\text { gia }\end{array}$ & $\begin{array}{l}\text { Minimizar os } \\
\text { impactos desse } \\
\text { processo e } \\
\text { contribuir para a } \\
\text { melhoria da } \\
\text { qualidade de vida } \\
\text { desses idosos. }\end{array}$ & $\begin{array}{c}\text { Estudo } \\
\text { descrito e } \\
\text { de } \\
\text { abordagem } \\
\text { quanti- } \\
\text { qualitativa }\end{array}$ & $\begin{array}{c}\text { Idosos } \\
\text { Institucionalizados } \\
\text { que não possuem } \\
\text { atividades sociais, e } \\
\text { um trabalho de } \\
\text { fisioterapia, podem } \\
\text { ter a qualidade de } \\
\text { vida comprometida. }\end{array}$ \\
\hline 13 & $\begin{array}{c}\text { Qualidade de } \\
\text { vida da pessoa } \\
\text { idosa conforme } \\
\text { nível de } \\
\text { institucionalizaçã } \\
\text { o }\end{array}$ & $\begin{array}{c}\text { Araújo e } \\
\text { Bós / } \\
(2017)\end{array}$ & $\begin{array}{c}\text { Estudo } \\
\text { Interdisci } \\
\text { plinar } \\
\text { Envelhece } \\
\quad r\end{array}$ & $\begin{array}{c}\text { Pretende-se } \\
\text { apresentar à } \\
\text { sociedade e às } \\
\text { autoridades } \\
\text { públicas, dados } \\
\text { provenientes de } \\
\text { uma abordagem } \\
\text { diferenciada dessa } \\
\text { parcela da } \\
\text { população idosa, } \\
\text { com tendências a } \\
\text { um crescimento } \\
\text { vertiginoso. }\end{array}$ & $\begin{array}{c}\text { Estudo } \\
\text { transversald } \\
\text { e } \\
\text { abordagem } \\
\text { qualitativa }\end{array}$ & $\begin{array}{l}\text { Ao comparar os } \\
\text { resultados da } \\
\text { qualidade de vida } \\
\text { em pares de grupos } \\
\text { constatou-se que } \\
\text { quase todas as } \\
\text { comparações foram } \\
\text { significativas, } \\
\text { demonstrando que } \\
\text { todos os grupos são } \\
\text { diferentes entre si } \\
\text { em cada um dos } \\
\text { domínios e facetas. }\end{array}$ \\
\hline 14 & $\begin{array}{c}\text { Avaliação } \\
\text { nutricional de } \\
\text { idosos residentes } \\
\text { em instituições } \\
\text { de longa } \\
\text { permanência }\end{array}$ & $\begin{array}{l}\text { Lima et al. / } \\
\text { (2017) }\end{array}$ & $\begin{array}{c}\text { Revista } \\
\text { Baiana de } \\
\text { Enfermag } \\
\text { em }\end{array}$ & $\begin{array}{l}\text { Acolher idosas que } \\
\text { conseguem } \\
\text { desenvolver suas } \\
\text { Atividades de Vida } \\
\text { Diária, sendo } \\
\text { mantida } \\
\text { financeiramente } \\
\text { por doações } \\
\text { e com } 70 \% \text { do } \\
\text { benefício de } \\
\text { aposentadoria. }\end{array}$ & $\begin{array}{c}\text { Estudo } \\
\text { descritivo e } \\
\text { transversal } \\
\text { de } \\
\text { abordagem } \\
\text { quantitativa }\end{array}$ & $\begin{array}{l}\text { Sabe-se que os } \\
\text { problemas } \\
\text { relacionados ao } \\
\text { estado nutricional } \\
\text { de idosos acelera o } \\
\text { surgimento de } \\
\text { fragilidade e } \\
\text { vulnerabilidade. } \\
\text { Mostrando risco de } \\
\text { desnutrição e } \\
\text { podendo dificultar } \\
\text { na recuperação das } \\
\text { doenças crônicas e } \\
\text { contribuindo para } \\
\text { morbimortalidade. }\end{array}$ \\
\hline 15 & $\begin{array}{c}\text { Condições de } \\
\text { saúde de idosos } \\
\text { institucionalizado } \\
\text { s: contribuições } \\
\text { para ação } \\
\text { interdisciplinar e } \\
\text { promotora de } \\
\text { saúde }\end{array}$ & $\begin{array}{l}\text { Silva et al. / } \\
\text { (2019) }\end{array}$ & $\begin{array}{l}\text { Caderno } \\
\text { Brasileiro } \\
\text { de } \\
\text { Terapia } \\
\text { Ocupacio } \\
\text { nal }\end{array}$ & $\begin{array}{c}\text { Caracterizar } \\
\text { clinicamente os } \\
\text { idosos residentes } \\
\text { em uma ILPI } \\
\text { filantrópica de uma } \\
\text { cidade do interior } \\
\text { do RS, visando o } \\
\text { planejamento de } \\
\text { ações } \\
\text { interdisciplinares } \\
\text { que preservem a } \\
\text { independência e/ou } \\
\text { previnam }\end{array}$ & $\begin{array}{c}\text { Estudo } \\
\text { transversal } \\
\text { de } \\
\text { abordagem } \\
\text { quantitativa }\end{array}$ & $\begin{array}{l}\text { Desta forma, aos } \\
\text { profissionais que } \\
\text { atuam neste } \\
\text { contexto é } \\
\text { necessário um olhar } \\
\text { para o sujeito idoso } \\
\text { de forma } \\
\text { biopsicossocial, } \\
\text { analisando suas } \\
\text { demandas de } \\
\text { cuidados físicos, } \\
\text { sem negligenciar } \\
\text { suas relações }\end{array}$ \\
\hline
\end{tabular}




\begin{tabular}{|c|c|c|c|c|c|c|}
\hline & & & & $\begin{array}{c}\text { dependência } \\
\text { funcional desses } \\
\text { idosos. }\end{array}$ & & $\begin{array}{l}\text { sociais, autonomia, } \\
\text { qualidade de vida, } \\
\text { afetividade, } \\
\text { sexualidade e saúde } \\
\text { mental, } \\
\text { proporcionando- } \\
\text { lhes atividades que } \\
\text { atendam às suas } \\
\text { necessidades de } \\
\text { maneira singular. }\end{array}$ \\
\hline 16 & $\begin{array}{c}\text { Qualidade de } \\
\text { vida de idosos } \\
\text { institucionalizado } \\
\text { s com e sem } \\
\text { sinais de } \\
\text { depressão }\end{array}$ & $\begin{array}{l}\text { Juniori et } \\
\text { al. / (2019) }\end{array}$ & $\begin{array}{c}\text { Revista } \\
\text { Brasileira } \\
\text { de } \\
\text { Enfermag } \\
\text { em }\end{array}$ & $\begin{array}{c}\text { Comparar a } \\
\text { qualidade de vida } \\
\text { (QV) de idosos } \\
\text { residentes em } \\
\text { instituições de } \\
\text { longa permanência } \\
\text { com ou sem sinais } \\
\text { de depressão, e } \\
\text { identificar } \\
\text { variáveis sociais, } \\
\text { de atividade física, } \\
\text { lazer, saúde e } \\
\text { atividades básicas } \\
\text { da vida diária } \\
\text { (ABVD) que se } \\
\text { correlacionam aos } \\
\text { escores de QV. }\end{array}$ & $\begin{array}{c}\text { Estudo } \\
\text { transversa, } \\
\text { descritivo, } \\
\text { com } \\
\text { abordagem } \\
\text { quantitativo }\end{array}$ & $\begin{array}{c}\text { Assim, em relação } \\
\text { ao estado mental } \\
\text { observa-se que a } \\
\text { orientação } \\
\text { preservada, a } \\
\text { coerência do } \\
\text { discurso, o } \\
\text { comportamento } \\
\text { adequado a } \\
\text { orientação espacial } \\
\text { e temporal estão } \\
\text { menos associados } \\
\text { ao risco de cair do } \\
\text { que os seus opostos. }\end{array}$ \\
\hline
\end{tabular}

Fonte: dados da Pesquisa, 2020.

No tocante ao período de publicação entre os estudos selecionados, as pesquisas apresentaram predomínio os anos de 2014 e 2017, com 4 publicações cada ano, sendo 8 (50\%) do total das publicações da amostra. Referente à revista, pode-se perceber que os artigos encontrados na base de dados LILACS, SCIELO e MEDLINE foram publicados em diferentes revistas, destaca-se: Revista Brasileira de Enfermagem, Revista Baiana de Enfermagem, Acta Paul Enfermagem, Revista Brasileira Promoção da Saúde, Revista Kairós Gerontologia, Estudo Interdisciplinar Envelhecer, Ciência e Saúde Coletiva, Caderno Brasileiro de Terapia Ocupacional e Revista Aletheia.

Desta forma, de modo mais específico, observou-se que a Revista Kairós Gerontologia se configurou como a de maior prevalência, apresentando 4 (31,25\%) obras na amostra desta pesquisa. Os objetivos propostos pelos estudos analisados, em sua maioria, tinham como finalidade avaliar a qualidade de vida de idosos frágeis institucionalizados, bem como minimizar os impactos desse processo e contribuir para a melhoria da qualidade de vida desses idosos.

Dentre o método de estudo utilizado pelas pesquisas selecionadas e analisadas, percebe-se uma diversidade entre as pesquisas, tendo entre elas, 2 (12,5\%) artigos com métodos de estudo transversal de abordagem quantitativa, 2 (12,5\%) artigos com métodos de 
estudo transversal de abordagem qualitativo, 3 (18,75\%) artigos de estudo descritivo transversal, $1(6,25 \%)$ artigo de estudo descritivo transversal de abordagem quantitativa, 3 $(18,75 \%)$ artigo de estudo descritivo de abordagem qualitativa, 1 (6,25\%) artigo de estudo descritivo de abordagem quantitativa, $1(6,25 \%)$ artigo de estudo cognitivo, $1(6,25 \%)$ artigo de estudo semi-estruturada de abordagem qualitativa, 1 (6,25\%) artigo de estudo intervenção aberta de abordagem quantitativa, 1 (6,25\%) artigo de estudo de campo de abordagem qualitativa.

Para que fosse realizada uma melhor discussão dos resultados dos artigos selecionados da amostra, que discorreram sobre o tema do estudo, onde buscou-se verificar a perspectiva dos idosos institucionalizados acerca da qualidade de vida, optou-se pela realização de duas categorias acerca do tema: 01) Qualidade de Vida do Idoso Institucionalizado, e 02) Percepção do Idoso Institucionalizado.

\section{Categoria 01: Qualidade de vida do idoso institucionalizado}

Ao analisar as qualidades especiais desses idosos, compete a ILPI proporcionar uma assistência gerontogeriátrica regressada para as precisões dos seus residentes. Para isto, faz-se indispensável que as instituições incluam ingresso aos serviços de uma equipe multiprofissional qualificada para as tarefas na área gerontológica. Quanto componente da equipe multidisciplinar o enfermeiro precisa concretizar a estimativa multidimensional do idoso, motivada nos princípios da gerontologia, com a finalidade de buscar e motivar o estado funcional, a saúde mental e social do idoso (Oliveira e Tavares, 2014).

O envelhecimento tende a ser frágil e deplorável para muitos idosos. Com prioridade, eles se veem frente a solidão, à falta de apoio social, a adversidade em lidar com o respectivo processo de envelhecimento, com o falecimento do companheiro, a rejeição familiar, as dificuldades para se manter completamente, o que também pode provocar doenças físicas e psíquicas. A respectiva alteração social dos últimos anos, contendo os novos princípios familiares, o avanço tecnológico e científico de dominação dos mais jovens e o acréscimo de mulheres no trabalho fora do lar, são motivos que colaboram para a ausência de base aos idosos (Marin et al., 2012).

Gradualmente os estudos vem estabelecendo orientações para as ILPI, conforme modificações de como ingerir os alimentos, esse número faz-se ainda menor quando é relacionado à avaliação da qualidade de vida. Deste modo, o presente estudo tem como 
propósito investigar o impacto das mudanças de deglutição na qualidade de vida em idosos (Cardoso et al., 2014).

O entendimento da qualidade do sono com os idosos institucionalizados é significativo para o desenvolvimento de plano capazes de observar às demandas crescentes dessas pessoas, tendo em conta que o sono impróprio pode intervir na saúde física e cognitiva, mas a frente podendo afetar arduamente a qualidade de vida desses indivíduos. Deste modo, os enfermeiros devem interceder na promoção de saúde com ações que reduzam ou previnam esses problemas, a iniciar com a educação em saúde e avaliação descrita e amplo da qualidade do sono (Mansano-Schlosser et al., 2014).

A qualidade de vida e a saúde são relevantes, amplas e complexos. Considera-se que as presenças de alguns aspectos são capazes de dar evidências de como encontra-se a situação de saúde e qualidade de vida do idoso institucionalizado. Todavia, para melhor compreensão dos potenciais, Qualidade de Vida do Idoso Institucionalizado, elaborou-se uma imagem com os principais achados compactados a partir dos estudos encontrados, observou-se que os sintomas com maior impacto sobre a qualidade de vida dos idosos institucionalizados são: Depressão, doenças crônicas, incontinência urinaria, mobilidade, nutrição, fragilidade, isolamento, abandono, deglutição, problemas mentais e incapacidade motora (Pereira et al., 2015).

\section{Categoria 02: Percepção do idoso institucionalizado}

Constata-se que a conservação da condição da evolução mental e motora da pessoa idosa requer bastante atenção, principalmente, quando se trata das ILPI, já que o idoso institucionalizado se mostra mais prejudicado ao desenvolvimento da redução mental e motora. É imprescindível o desenvolvimento do amparo por parte dos profissionais da saúde, com foco para estabelecer a melhor qualidade de vida no envelhecimento ativo e saudável desses idosos, para que permitam a prevenção desses feitios na classe idosa. Assim, o alvo deste estudo é avaliar o desenvolvimento das ações que estimulam as habilidades dos idosos institucionalizados (Mariano et al., 2020).

Através deste argumento, estima-se a percepção dos idosos sobre as condições de vida e o processo de institucionalização, é de grande estima científica e social, já que é imprescindível implementar instabilidades de intercessão, como instruções geriátricos e políticas sociais, procurando causar o bem-estar deste grupo de pessoas que, de tal maneira no mundo atual, quão no futuro, compõe boa parte da população (Evangelista et al., 2014). 
Destaca-se a obrigação urgente da priorização do idoso na formação de políticas e de movimentação dos conselhos para a qualidade dos serviços e, também de diretrizes intersetoriais que consigam qualificar o cuidado com a pessoa idosa institucionalizada. Além de tudo, consegue perceber que muito pouco é feito pelo governo para acolher às demandas específicas na atenção ao idoso institucionalizado. Tal adversidade, muitas vezes, poderia ser diminuída por um maior diálogo entre as instituições na finalidade de obter respostas para os problemas enfrentados e acrescentar experiências exitosas alcançadas, ressaltando a importância da movimentação do capital social onde há pequena atuação do Estado (Lacerda et al., 2017).

O acréscimo da perspectiva de vida, próximo à transformação de estimas familiares, induz a maior busca da família pela ILPI. Ora em diante o motivo de analisar a importância nacional desenvolver pesquisas e números igualitários em parceria com o IBGE e o IPEA, com aceites à concretização de uma melhor idealização no que se refere às políticas públicas voltada para o idoso (Carvalho, 2014). Torna-se efetivo desenvolver e aprofundar indagações que englobem o idoso em categoria de institucionalização, especialmente em semelhança à depressão. A saúde do idoso é um amplo campo para a obra de conhecimento em volta de ações que possam cooperar para as políticas públicas de saúde, do mesmo modo quanto para os métodos dos profissionais da saúde nas ILPI (Guths et al., 2017).

\section{Considerações Finais}

Diante do exposto, o estudo foi capaz de mostrar que o idoso que reside, habita em Instituição de Longa Permanência (ILP) é necessário estar ativo, dinâmico, preparado a realizar suas atividades de vida diária, a fim de conseguir sua qualidade de vida, harmonizar saúde e favorecer um envelhecimento saudável.

Nesse caso, ponderando os achados, apresentou que fatores de risco mais comuns são: doenças crônicas - degenerativas, pacientes com incontinência urinária, com depressão, com nutrição desequilibrada, solidão, fragilidade, isolamento, abandono e incapacidade. Advertese, que os profissionais das ILPI têm de observar para essas condições, uma vez que ajudam como sinalizadores para a equipe multidisciplinar agir de forma precoce, conseguindo estabelecer medidas preventivas que garanta a promoção da qualidade de vida do Idoso. 


\section{Referências}

Abreu T. A. et al. (2017). Reflexões acerca dos Impactos Psicossociais da Institucionalização de Idosos no Brasil. Revista Kairós Gerontologia, v. 20, n. 2, p. 333-352.

Araújo A. M. \& Bós A. J. G. (2017). Qualidade de vida da pessoa idosa conforme nível de institucionalização. Estud. interdiscipl. Envelhec, Porto Alegre, v. 22, n. 3, p. 137-152.

Brandão V. C. \& Zatt G. B. (2015). Percepção de idosos, moradores de uma instituição de longa permanência de um município do interior do Rio Grande do Sul, sobre qualidade de vida. Aletheia, Canoas, v. 46, p. 90-102.

Botelho L. L. R, et al. (2011). Método da revisão integrativa nos estudos organizacionais. Gestão e Sociedade, v. 5, n. 11, p. 121-136. https://doi.org/10.21171/ges.v5i11.1220.

Broome M. E. et al. (2000). Integrative literature reviews for the development of concepts. Concept development in nursing: foundations, techniques and applications. Philadelphia, v. 4, n. 2, p. 231-250.

Camarano A. A. \& Kanso S. (2010). As instituições de longa permanência para idosos no Brasil. Camarano AA. Cuidados de longa duração para a população idosa: um novo risco social a ser assumido?, IPEA, Rio de Janeiro, p.187-212.

Cardoso S. V. et al. (2014). O impacto das alterações de deglutição na qualidade de vida de idosos institucionalizados. Revista Kairós Gerontologia, v. 17, n. 1, p. 231-245.

Carvalho V. L. (2014). Perfil das instituições de longa permanência para idosos situadas em uma capital do Nordeste. Cad. Saúde Colet, v. 22, n. 2, p. 184-191. https://doi.org/10.1590/1414-462X201400020012.

Cordeiro L. M, et al. (2015). Qualidade de vida do idoso fragilizado e institucionalizado. Acta Paul. Enferm, v. 28, n. 4, p. 361-366. http://dx.doi.org/10.1590/1982- 0194201500061.

Evangelista R. A. et al. (2014). Perceptions and experiences of elderly residents in a nursing home. Rev. esc. enferm. USP, São Paulo, v. 48, n. 2, p. 81-86. https://doi.org/10.1590/S0080623420140000800013.

Gomes J. B. \& Reis L. A. (2016). Descrição dos sintomas de Ansiedade e de Depressão em idosos institucionalizados no interior da Bahia, Brasil. Revista Kairós Gerontologia, v. 19, n. 1, p. 175-191.

Gonçalves D. et al. (2014). Avaliação das funções cognitivas, qualidade de sono, tempo de reação e risco de quedas em idosos institucionalizados. Estud. interdiscipl. Envelhec, Porto Alegre, v. 19, n. 1, p. 95-108.

Guths J. F. S. et al. (2017). Sociodemographic profile, family aspects, perception of health, functional capacity and depression in institutionalized elderly persons from the north coastal region of Rio Grande do Sul, Brazil. Rev. bras. geriatr. gerontol., Rio de Janeiro , v. 20, n. 2, p. 175-185. https://doi.org/10.1590/1981-22562017020.160058. 
Jerez-Roig J. et al. (2016). Self-perceived health in institutionalized elderly. Ciênc. saúde coletiva, v. 21, n. 11, p. 3367-3375.

Juniori G. S. et al. (2019). Qualidade de vida de idosos institucionalizados com e sem sinais de depressão. Rev Bras Enferm, v. 72, n. 2, p. 135-141.

Lacerda T. T. B. et al. (2017). Characterization of long-term care facilities for the elderly in the metropolitan region of Belo Horizonte. Rev. Bras. Geriatr. Gerontol, v. 20, n. 6, p. $743-$ 753.

Lini E. V. et al. (2016). Factors associated with the institutionalization of the elderly: a casecontrol study. Rev. bras. geriatr. gerontol., Rio de Janeiro, v. 19, n. 6, p. 1004-1014. http://dx.doi.org/10.1590/1981-22562016019.160043.

Leite S. C. C. \& Caldeira A. P. (2015). Therapeutic workshops and psychosocial rehabilitation for institutionalised leprosy patients. Ciênc. saúde coletiva, v. 20, n. 6, p. 18351842.

Lima A. P. M. et al. (2016). Qualidade de vida sob a óptica da pessoa idosa institucionalizada. Revista Brasileira em promoção da Saúde, v. 29, p. 14-26. https://doi.org/10.5020/18061230.2016.p14.

Lima A. P. M. et al. (2017). Avaliação nutricional de idosos residentes em instituições de longa permanência. Rev. Baiana Enfermagem, v. 31, n. 4, p. 20-27.

Mariano P. P. et al. (2020). Desenvolvimento de atividades de estímulo cognitivo e motor: perspectiva de idosos institucionalizados. Esc. Anna Nery, Rio de Janeiro, v. 24, n. 3. https://doi.org/10.1590/2177-9465-ean-2019-0265.

Marin M. J. S. et al. (2012). Compreendendo a história de vida de idosos institucionalizados. Rev. bras. geriatr. gerontol., Rio de Janeiro, v. 15, n. 1, p. 147-154. https://doi.org/10.1590/S1809-98232012000100016.

Mansano-Schlosser T. C. et al. (2014). Idosos institucionalizados: organização cronológica das rotinas diárias e qualidade do sono. Rev. Bras. Enfermagem, v. 67, n. 4, p. 610-616.

Mendes K. D. S. et al. (2008). Revisão integrativa: método de pesquisa para a incorporação de evidências na saúde e na enfermagem. Texto contexto - enferm, v. 17, n. 4. P. 758-764.

Miranda G. M. D. et al. (2016). Population aging in Brazil: current and future social challenges and consequences. Rev. Bras. Geriatr. Gerontol, v. 19, n. 3, p. 507-519.

Néri A. L. et al. (2012). Relationships between gender, age, family conditions, physical and mental health, and social isolation of elderly caregivers. International Psychogeriatrics, v. 24, n. 3, p. 472-483.

Oliveira P. B. \& Tavares D. M. S. (2014). Condições de saúde de idosos residentes em Instituição de Longa Permanência segundo necessidades humanas básicas. Rev. Bras. Enfermagem, v. 67, n. 2, p. 241-246. https://doi.org/10.5935/0034-7167.20140032. 
Pereira D. S. et al. (2015). Quality of life and the health status of elderly persons: a population-based study in the central sertão of Ceará. Rev. Bras. Geriatr. Gerontol, v. 18, n. 4, p. 893-908.

Reis M. G. et al. (2014). Quedas em idosos com perturbações mentais residentes em unidade de saúde de longa duração. Revista Portuguesa de Enfermagem de Saúde Mental, v. 2, n. 1, p. 33-39.

Roman A. R. \& Friedlander M. R. (2008). Revisão integrativa de pesquisa aplicada à enfermagem. Cogitare Enferm, v. 3, n. 2, p. 109-112.

Silva R. S. et al. (2019). Condições de saúde de idosos institucionalizados: contribuições para ação interdisciplinar e promotora de saúde. Cad. Bras. Ter. Ocup., São Carlos, v. 27, n. 2, p. 345-356. http://dx.doi.org/10.4322/2526-8910.ctoao1590.

Silva A. C. \& Neves R. (2017). Programas de atividade física para pessoas idosas institucionalizadas - contextos e práticas. Revista Kairós - Gerontologia, v. 20, n. 4, p. 9-25. https://doi.org/10.23925/2176-901X.2017v20i4p09-25.

Silva R. S. et al. (2019). Condições de saúde de idosos institucionalizados: contribuições para ação interdisciplinar e promotora de saúde. Cad. Bras. Ter. Ocup, São Carlos, v. 27, n. 2, p. 345-356. https://doi.org/10.4322/2526-8910.ctoao1590.

Whittemore R. \& Knafl K. (2005). The integrative review: updated methodology. Journal of advanced nursing, v. 52, n. 5, p. 546-553.

\section{How to cite this article (APA format):}

Luna, Cícera Alves de; Sousa, Allex Alves Sobral de; Queiroz, Iasmim Belém Silva; Sampaio, Samyra Maria Lima; Gurgel, Lucineide Coqueiro; Luna, Thayná Bezerra de; Sousa, Carmelita Maria Silva; Cordeiro, Abigail de Almeida; Luz, Dayse Christina Rodrigues Pereira; Santana, Willma José de (2020). Perception of institutionalized elderly about quality of life: an integrative review. Am. In. Mult. J., Jul to Oct. (9) 5, 152-169.

Received: 08/01/2020;

Accepted: 08/18/2020. 